\title{
Corpus
}

Archivos virtuales de la alteridad americana

Vol. 8, No 2 | 2018

Julio / Diciembre 2018

\section{La vida impropia}

\section{Florencia Garramuño}

\section{OpenEdition}

\section{Journals}

Electronic version

URL: http://journals.openedition.org/corpusarchivos/2716

DOI: 10.4000/corpusarchivos. 2716

ISSN: 1853-8037

\section{Publisher}

Diego Escolar

\section{Electronic reference}

Florencia Garramuño, « La vida impropia », Corpus [En línea], Vol. 8, No 2 | 2018, Publicado el 25 diciembre 2018, consultado el 21 abril 2019. URL : http://journals.openedition.org/ corpusarchivos/2716 ; DOI : 10.4000/corpusarchivos.2716

This text was automatically generated on 21 April 2019.

Licencia Creative Commons: Atribución-NoComercial 2.5 Argentina (CC BY-NC 2.5 AR) 


\section{La vida impropia}

\section{Florencia Garramuño}

1 Una noción de vida impropia, impersonal, está siendo discutida y articulada en algunas prácticas culturales y estéticas latinoamericanas contemporáneas. En muchas de ellas se elaboran formas de acceder a - de narrar, de exhibir, de discutir - una vida anónima que viene a reemplazar la vida individual o subjetiva, exhibiendo una preocupación por la vida - o lo viviente - que ya no se reduce a la preocupación por la vida de un sujeto, o de un pueblo, o de una comunidad; no se reduce ni siquiera a la noción misma de vida humana aunque, obviamente, también la incluya, junto a otras formas de vida que la acompañan, la completan, y la dislocan.

2 En la Bienal de São Paulo de 2016, titulada Incerteza viva, un filme de Jonathas de Andrade sustituye -o complementa- la pregunta por la vida con la interrogación por la muerte. En o peixe (2016), el realizador acompañó a pescadores de Alagoas. Los sigue en sus canoas, internándose en mareas y manglares, detenidos a la espera del momento adecuado para, con sus redes o arpones, capturar la presa. Son diversos los hombres, con sus torsos desnudos; de distintas edades; pero en todos, los músculos que han sido definidos por el trabajo de la pesca parecen también propicios para el abrazo ritual en el que se unen, pescador y pez, en el momento final -límite - en el que el pez expira.

3 La vida, la muerte: las imágenes oscilan con la luz que atraviesa las hojas de los árboles debajo de los cuales se desplazan las canoas. En los cuerpos, la luz reverbera sobre músculos y rostros donde late la vida ya vivida y la vida aun por vivir. El viento susurra entre las hojas, las olas golpean la canoa.

4 Me imagino a esos peces, enormes, del norte del Brasil - tambaqui, filhote, piracicaba-, sacudiéndose en sus estertores de muerte sobre el piso de la canoa. Los veo inquietos, desasosegados, y veo cómo voltean esas canoas frágiles y vuelven así al agua y a su hábitat; quién sabe, tal vez también a la vida. Pienso que los pescadores han encontrado en ese abrazo la última herramienta en una labor de depredación inmemorial; han llegado a él por experiencia de vida. Pero el abrazo los ha llevado, como puede verse en la transformación de los rostros y en los gestos con los que acompañan a los peces a morir, afuera de sí mismos; los confronta, en un cuerpo a cuerpo con sus presas - no exento de erotismo-, con la muerte misma y el largo intervalo en el que la vida deja de palpitar en 
esos otros cuerpos. El abrazo calma a los peces y afecta a los pescadores. La cámara filma ese intervalo entre la vida y la muerte todo el tiempo que sea necesario; en tiempo real, la filmación filma exactamente la muerte, es decir: el tiempo que lleva morir.

El filme no sigue ni la vida individual de los pescadores, ni sus costumbres y herramientas, ni su entorno sociocultural. No los entrevista, no se ve a los pescadores hablar. Tampoco se detiene en la naturaleza de los peces, sus formas de vida, sus modos de subsistencia, el hábitat de su especie. Se trata de 36 minutos en los que, entre canoas y árboles, por ríos inmensos, la cámara acompaña a los pescadores en su pesca. El contacto entre cuerpos y seres anónimos superpone vida y muerte, alisa una suerte de continuidad entre una y otra. La misma continuidad que, en el film, se teje entre pescador y pescado, entre predador y presa, entre hombre y animal.

Como en el filme de Jonathas de Andrade, son muchas las prácticas contemporáneas que han abandonado la vida individual y subjetiva para construir sus narrativas e imágenes a partir de una noción de vida impersonal que desprende las historias de la vida de un sujeto, de un individuo, para concentrarse, en cambio, en una vida.

7 "Nadie mejor que Charles Dickens captó qué es una vida", escribió Deleuze en su ensayo póstumo, Inmanencia: una vida, refiriéndose a "Our mutual friend", la novela en la que Dickens capta el momento preciso entre la vida y la muerte en que la vida ya no es la vida de una persona en particular, de un individuo, sino la vida en tanto energía - esa "spark of life", en palabras de Dickens - , que habita en un cuerpo pero es irreductible a él. Una vida, dice Deleuze, y subraya una. Su objetivo es separar y distinguir la inmanencia pura de cualquier tipo de transcendencia (Deleuze 2001, p. 28).

¿Pero que es, exactamente, una vida?

9 ¿Cuál sería la potencia de ese movimiento que, en algunas artes contemporáneas, la exhibe?

10 Se trata de un vida impropia en el sentido de que en ellas la vida no se define por su pertenencia a alguien en particular, a un sujeto, sino en tanto energía o "spark", en palabras de Dickens, que trasciende esos sujetos. Más allá, incluso, de los cuerpos individuales. En Mano de Obra (2002), de Diamela Eltit, por ejemplo, se trata de la vida de un grupo de trabajadores de supermercado en el Chile neoliberal de los años 2000 pero, como el título ya anticipa, la narración va más allá de ese grupo y se desplaza hacia una reflexión mucho más amplia sobre el destino o la historia de la "mano de obra" chilena (e, incluso, en un gesto de confusión de localidades y experiencias muy típico de cierta narrativa contemporánea, del destino de la mano de obra en general, aún más allá de Chile o, en todo caso, donde Chile vendría a ser un ejemplo, una instancia - tal vez extrema, en cierto sentido - de ese mundo contemporáneo). ${ }^{1}$ De hecho, el texto utiliza una primera persona singular (en la primera parte) y plural (en la segunda) que se vacía de interioridad para hacer emerger unos personajes siempre privados del poder de decir yo, despojados de la posiblidad - incluso - de tener un rostro. Un montaje de tiempos heterogéneos desplaza esos sujetos para interrumpir el presente neoliberal, dejando ver agenciamientos colectivos - siempre contingentes - en los cuales figuras de lo impersonal y anónimo muestran su potencial para pensar acciones colectivas más allá de los destinos y posibilidades de los individuos. Vestigios, discursos, memorias y fragmentos de mundos diversos se arremolinan en un texto que busca, en la inestablidad de sus discursos, otros modos de pensar experiencias compartidas de modos complejos y críticos. 
11 Si es verdad que la deconstrucción de la subjetividad es uno de los grandes motivos del trabajo filosófico contemporáneo (Roberto Esposito 2009, 2012; Jean-Luc Nancy 1991), es importante entender que la pregunta apunta hacia la deconstrucción de la interioridad, del "self", de la presencia, de la consciencia e incluso de la "autoridad" (Jean-Luc Nancy 1991). ${ }^{2}$

12 Sin propiedad, impropia, la vida no solo carece entonces de identificaciones o adjetivos que la individualicen sino que se vuelve una reflexión sobre lo común y sobre la experiencia compartida. Es, en ese sentido, una vida impersonal, donde lo impersonal viene a instituirse en vector que deconstruye la vida subjetiva para convertir estas prácticas en una discusión sobre la vida de una colectividad o, en palabras de Jean-Luc Nancy, en una elaboración sobre la coexistencia: sus posibilidades, sus limitaciones, pero también sus fortunas o potencialidades. ${ }^{3}$

13 En Imemorial, de Rosângela Rennó, ese vector impersonal atraviesa la recuperación de una historia sumida en un mar de amnesia. En su instalación, realizada con fotografías recuperadas de los archivos de la empresa constructora de la nueva capital en Brasília, NOVACAP, Rennó exhibió la amensia social y la persistencia espectral de sus violencias. La instalación, de 1994, fue presentada por primera vez en una exposición titulada Revendo Brasília, curada por Alfons Hug, que buscó "un abordaje crítico de la capital brasileña, aprovechando los recursos de la fotografía artística” (Hug y Salles, 2015 p. 23). Se trataba de revisar, mediante la fotografía, las peculiaridades de una ciudad que se propuso- según la idea de Lúcio Costa -como un centro irradiador de desarrollo y de cultura para el Brasil, sostenido en la utopía de una revolución estética que fue truncada por las dificultades de una modernidad dependiente y por una dictadura militar que en poco menos de una década desde su fundación llevó al país por el camino de una violenta modernización autoritaria (las imágenes y los discursos de los diputados brasileños en el congreso de Brasília que destituyó en un golpe el gobierno de Dilma Rousseff resultaron un nuevo avatar de esa confluencia de tiempos heterogéneos en el escenario de Brasília). La artista recuperó las fichas de los empleados de la empresa, muchos de ellos muertos en masacres, como la de Pacheco, instrumentadas por una policía que reprimía las demandas de los trabajadores por mejores condiciones de trabajo. Rennó amplió las fotografías carnet que encontró en esas fichas para realizar con ellas una serie de retratos de $(60 \mathrm{x} 40 \mathrm{~cm}$.). Dispuestas en la sala repitiendo el diseño en cruz del Plano Piloto de Lúcio Costa sobre bandejas de hierro, las fotografías se ubican sobre las paredes y sobre el suelo de la sala. En el suelo, impresas en película ortocromática, las fotografías de los muertos durante la construcción de la nueva capital emanan un halo espectral, pero los nombres de esos muertos - que también estaban en las fichas que Rennó recuperó - han sido olvidados en el antimonumento que erigió la artista. Solo al pie de las fotografías, cual epígrafes, figuran los números de contratación de los obreros. Perder el nombre es entonces un modo de recuperar una vida y un destino anónimo. El anonimato resulta un dispositivo poderoso para hacer evidente la persistencia - aun espectral - de una vida - una vida- sin procurar una restitución o redención individual. Frente a la restitución, Rennó eligó el poder de la sobrevivencia. Al utilizar esas viejas fotografías y hacer evidente el nuevo valor que la intervención de la artista produce sobre esos restos, Imemorial apunta al sentido latente de un pasado que repercute sobre el presente: la activación de la sobrevivencia del pasado ilumina con su sombra paradójica los proyectos truncos del pasado. 
14 Es preciso distinguir, sin embargo, entre lo impersonal y lo anónimo. Mientras que lo impersonal hace referencia a un modo de alejarse de las propiedades y singularidades subjetivas de esas vidas, lo anónimo apunta en cambio al olvido definitivo del nombre. Aunque no son evidentemente lo mismo, tanto lo impersonal como lo anónimo aparecen como dispositivos diferenciados que quieren distanciarse de la individualidad de una historia. En Cosas, de Edgardo Dobry, un libro de poemas que debería ser leído como elegía a la muerte de su madre, la concentración en las cosas, precisamente, de un recuerdo tejido en el anonimato de seres, hace de esa anonimia un instrumento poderoso en la transmisión de una emoción sin sujeto, un afecto impersonal que es, justamente por impersonal, más poderoso. La emoción, dijo Didi-Huberman, no dice "yo" (DidiHuberman, 2014).

"Lo anónimo - señala Rancière - no es el cuerpo colectivo con el que la tradición revolucionaria ha identificado fácilmente la subjetivación política. No es el mundo silencioso de los largos ciclos de la vida material y de las mentalidades populares que los historiadores han opuesto - es decir, han hecho complementario - al universo de los lenguajes y de las decisiones superiores (...) Lo anónimo no es una sustancia sino un proceso de distanciamiento puesto en cuestión permanentemente (Rancière 1994, pp. 79-80; el subrayado es mío).

En este contexto, tal vez pensar la vida más allá de la persona y del individuo sea un modo de reemplazar el lugar del sujeto - “Who comes after the Subject?", se pregunta Jean-Luc Nancy; pero cabría preguntar What comes? (Nancy 1990)- por una noción de vida impersonal y anónima que, más allá de las singularidades individuales y personales, busque y diseñe - imagine - modos de resistencia a las constricciones identitatarias y personales, negándose a tomar la interioridad del individuo como refugio. Para Foucault, esa misma vida impersonal es aquello que escapa al poder, que se le escurre, que lo enfrenta y que a su vez elude - incluso sin proponérselo - las formas de subjetivación que el poder formula. ${ }^{4}$

En estas prácticas, además, la opción por una vida impersonal permite alisar una suerte de continuidad entre vida humana y naturaleza, entre vida humana y otras formas de vida, incluso cuando esa continuidad suponga -como en el filme de Andrade- la violencia. Aun allí, esa continuidad permite despegarnos de los poderes o impotencias de los sujetos para concentrarnos en la chispa de vida -esa "spark"-, centrarnos en la energía que evidencia esa vida. La vida vista desde el prisma de la experiencia impersonal parece abrir a nuestro mundo la exposición de una potencia de vida que, más allá del acceso al poder de los sujetos, sobrevive e insiste. En tiempos tan sombríos como los que atravesamos, me parece ver allí una forma nada desdeñable de otorgar a los pueblos, y a nuestro mundo, un intenso poder de aparición.

17 Pero además, interrogar estas figuras de lo impersonal y de lo anónimo puede inspirarnos para la discusión de formas de organizar la experiencia que ya no se sustenten sobre el predominio de lo individual ni de lo humano, predominio que estas mismas figuras de lo impersonal y anónimo evidencian ha resultado muy problemático -por no decir, en muchos sentidos, catastrófico.

18 ¿Qué nos dicen estas figuras - estas prácticas - del modo en que organizamos y comprendemos la experiencia en el mundo contemporáneo? 


\section{BIBLIOGRAPHY}

Andrade, J. de. (2016) O peixe. (filme). Brasil.

Deleuze, G. (2001). Pure Immanence: Essays on a life. New York: Urzone.

Didi-Huberman, G. (2014). "La emoción no dice "yo". Diez fragmentos sobre la libertad estética." En Didi-Huberman et al. Alfredo Jaar. La política de las imágenes. Santiago de Chile, Metales pesados, pp? (sólo números, i.e. 123-145)

Dobry, E. (2008). Cosas. Barcelona: Lumen.

Eltit, Diamela. Mano de obra. Santiago de Chile, Seix Barral, 2002

Foucault, M. (2007) “La vida: la experiencia y la ciencia”. En Gabriel Giorgi y Fermín Rodríguez, Ensayos sobre biopolítica. Excesos de vida. Buenos Aires, Paidós, .

Garramuño, F.(2016) “Dimensiones de lo impersonal en la cultura contemporánea.” Badebec, Vol. 5, No. 10, pp. 130-140, disponible en https://revista.badebec.org/index.php/badebec/article/ view/245/224

----.(2016) “O Outro avança sobre mim”, em estudos de literatura brasileira contemporânea, No. 48, p. $11-28,2016$

Hoyos, H. (2016). All the World's a Supermarket (And All the Men and Women Merely Shoppers). En Beyond Bolaño. The Global Latin American Novel. New York, Columbia University Press.

Hug, A. y Salles, E. (2015). Revendo Brasilia neu gesehen. Brasilia: Goethe-Institut.

Nancy, J. L.(1991) Introduction. En Eduardo Cadava, Peter O' Connor and Jean-Luc Nancy, Who Comes After the Subject? London, Routledge.

----. (2000). Being Singular Plural. Stanford, Stanford University Press, 2000

Rancière, J. (1994). Sobre políticas estéticas (Traductor, Arranz Lázaro, Manuel), Museu d'Art Contemporani de Barcelona, Universidad Autónoma de Barcelona.

Rennó, Rosângela.(1994) Serie Imemorial- Instalación.

\section{NOTES}

1. Véase sobre esto Héctor Hoyos (2015, pp.102-105).

2. Trabajé en detalle este texto de Eltit en "Dimensiones de lo impersonal en la cultura contemporánea" y, en una versión un tanto más extensa en portugués, en "O Outro avança sobre mim", publicado en estudos de literatura brasileira contemporânea, No. 48, p. 11-28, 2016.

3. Ver Jean-Luc Nancy (2000).

4. Foucault, Michel, en Giorgi y Rodríguez, (2007, pp. 41-58). 
AUTHOR

FLORENCIA GARRAMUÑO

Universidad de San Andrés/CONICET - florg@udesa.edu.ar 